Article

\title{
Experimental Methodology to Determine Thermal Conductivity of Nanofluids by Using a Commercial Transient Hot-Wire Device ${ }^{\dagger}$
}

\author{
Jose I. Prado $(\mathbb{D}$, Uxía Calviño $(\mathbb{D}$ and Luis Lugo *(D)
}

Citation: Prado, J.I.; Calviño, U.; Lugo, L. Experimental Methodology to Determine Thermal Conductivity of Nanofluids by Using a Commercial Transient Hot-Wire Device. Appl. Sci. 2022, 12, 329. https://doi.org/10.3390/ app12010329

Academic Editor: Roberto Zivieri

Received: 26 November 2021 Accepted: 23 December 2021 Published: 30 December 2021

Publisher's Note: MDPI stays neutral with regard to jurisdictional claims in published maps and institutional affiliations.

Copyright: (C) 2021 by the authors. Licensee MDPI, Basel, Switzerland. This article is an open access article distributed under the terms and conditions of the Creative Commons Attribution (CC BY) license (https:// creativecommons.org/licenses/by/ $4.0 /)$.
CINBIO, Universidade de Vigo, Grupo GAME, Departamento de Física Aplicada, 36310 Vigo, Spain; joseiglesias@uvigo.es (J.I.P.); uxia.calvino.barreiro@uvigo.es (U.C.)

* Correspondence: luis.lugo@uvigo.es; Tel.: +34-986-813-771

† This paper is an extended version of our paper published in Conference Proceedings: Uxía Calviño, Jose I. Prado and Luis Lugo. Setting up a transient hot wire device to determine the thermal conductivity of fluids. In Proceedings of the CYTEF 2020, Pamplona, Spain, 11-12 November 2020.

\begin{abstract}
The lack of a standard experimental procedure to determine thermal conductivity of fluids is noticeable in heat transfer processes from practical and fundamental perspectives. Since a wide variety of techniques have been used, reported literature data have huge discrepancies. A common practice is using manufactured thermal conductivity meters for nanofluids, which can standardize the measurements but are also somewhat inaccurate. In this study, a new methodology to perform reliable measurements with a recent commercial transient hot-wire device is introduced. Accordingly, some extensively studied fluids in the literature (water, ethylene glycol, ethylene glycol:water mixture 50:50 vol\%, propylene glycol, and $n$-tetradecane) covering the range 0.100 to $0.700 \mathrm{~W} \mathrm{~m}^{-1} \mathrm{~K}^{-1}$ were used to check the device in the temperature range 283.15 to $333.15 \mathrm{~K}$. Deviations between the collected data and the theoretical model, and repeatabilities and deviations between reported and literature values, were analyzed. Systematic deviations in raw data were found, and a correction factor depending on the mean thermal conductivity was proposed to operate with nanofluids. Considering all tested effects, the expanded $(k=2)$ uncertainty of the device was set as $5 \%$. This proposed methodology was also checked with $n$-hexadecane and magnesium-oxide-based n-tetradecane nanofluids.
\end{abstract}

Keywords: transient hot-wire; nanofluid; thermal conductivity; heat transfer fluids; glycol; $n$-alkanes

\section{Introduction}

Fluids are involved in most of the production and operation processes where, depending on the application and the working conditions of the equipment, particular characteristics are required. Reliable determination of thermophysical properties of these fluids is fundamental for an appropriated design of the equipment and processes. Among them, thermal conductivity is one of the most challenging to measure with high accuracy, and it is crucial in the proposal of new heat transfer fluids. The thermal conductivity of a fluid accounts for its ability to dissipate or absorb energy when a temperature gradient disturbs it from the thermal equilibrium [1]. The main difficulty to measure this property lies in the isolation of pure conduction from other heat transfer mechanisms, with convection being the most important. Due to the gravitational field of Earth, a temperature gradient in a fluid causes natural convection. Several efforts to measure the thermal conductivity under microgravity conditions showed that convection-free measurements are possible. However, the investment needed to obtain these conditions for the measurement hampers its routine use [1].

Over the years, different experimental devices have been developed over the different thermodynamic states. Until the 1970s, experimental work was focused on the development 
of methods to determine properties of simple samples and under moderate conditions [1,2]. Later, several techniques appeared that were methodologically innovative and contained a meticulous mathematical description of the experimental method to reach accurate values. Precise measurements allow one to suitably check fluid theories, including liquid and gas phases. However, the current scenario shows that the lack of standardized experimental procedures, techniques, and the preparation or well-recognized definition of complex samples itself largely lead to discrepancies. This issue hinders efforts to describe the real physical situation of such complex samples such as humid air, ionic melts (molten salts and ionic liquids), thermal energy storage materials, or nanofluids [3,4]. Likewise, it is well-established that among the different techniques, the transient hot-wire provides the most reliable absolute technique for the measurement of the thermal conductivity of gases, liquids, solids, melts, and nanofluids [2,5,6].

Nanofluids are an innovative kind of material based on well-dispersed nanoparticles within a bulk base fluid. Therefore, they constitute a two-phase thermodynamic system with a continuous phase (base fluid) and a dispersed phase (nanoparticles). Although the concept of thermal conductivity of a single-phase fluid cannot be extended to these complex thermodynamic systems, researchers are used to treat the effective thermal conductivity of the nanofluid as its own thermal conductivity (in a single-phase sense) [7]. It must be clear that we shall talk about 'thermal conductivity' of the nanofluid instead of referring to apparent thermal conductivity, for simplicity. Therefore, and according to Tertsinidou et al. [7] and Bioucas et al. [8], since the apparent thermal conductivity is not a true thermophysical property dependent only on thermodynamic state variables, special care should be taken to perform reliable experimental measurements of such a property.

Concerning studies devoted to nanofluids, researchers use transient hot-wire-based commercial devices to obtain thermal conductivity data [9], which can lead to a misuse of this equipment when the methods are not adequate for the object systems [3]. Therefore, it is necessary to establish some methodologies to avoid ill-determined data when using this kind of devices. Thereby, the determination of the effective thermal conductivity of nanofluids needs to be standardized, allowing for better comparison of data from different laboratories.

In this paper, we present a comprehensive implementation and methodology for the measurement of the thermal conductivity of fluids, especially nanofluids, by using an available commercial device based on the transient hot-wire method. The validation of the method, repeatabilities, and deviations between the experimental thermal conductivity values of several fluids and those from the available literature data were also detailed. The procedure and noted features of the particular measurements, advantages, and limitations have been reported and checked with $n$-hexadecane and $\mathrm{MgO} / n$-tetradecane nanofluid at 1,5 , and $10 \mathrm{wt} \%$. Accordingly, the main aim of the present work is to establish critical advices and suggestions in the experimental determination of thermal conductivity of fluids by means of the THW-L2 device from Thermtest Instruments. The use of these recommendations may lead to more reliable and usable measurements, by avoiding a source of discrepancies when using a new commercialized device.

\section{Thermal Conductivity Methods}

\subsection{General Statements}

Over the years, a plethora of scientific articles and authors have addressed different techniques for the determination of thermal conductivity [4,5], which can be classified into two main groups: steady-state methods and non-steady-state or transient methods [10]. This designation is based on the simplified energy equation, assuming that the sample is not moving (no convection), there is no heat generation in the fluid, the thermophysical properties are constant (small temperature gradients), fluids are isotropic, and Fourier law is applicable [3]:

$$
\lambda \nabla^{2} T=\rho c_{p} \frac{\partial T}{\partial t}
$$


where $\lambda$ is the thermal conductivity, $T$ the absolute temperature, $\rho$ the density, $c_{p}$ the isobaric heat capacity, and $t$ the time.

A steady-state technique records a measurement when the thermal state of the tested material reaches complete equilibrium; the temperature profile keeps constant, while the temperature of each point of the sample does not change with time. However, these systems have the disadvantages of requiring long time to reach the thermal equilibrium and involving larger samples than the transient ones. Nevertheless, steady-state methods have the advantage of one directional heat flow over a larger area, which accounts for measurements of samples with anisotropic thermal conductivity and composites $[3,10]$. Some widely spread steady state methods are guarded hot plate and heat flow meter, whose main features are enclosed in Table $1[10,11]$.

Table 1. Summary of some steady-state and transient methods for measuring thermal conductivity $[4,10]$.

\begin{tabular}{|c|c|c|c|c|c|}
\hline Method & $\begin{array}{c}\text { Temperature } \\
\text { Range (K) }\end{array}$ & 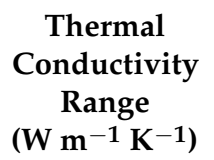 & $\begin{array}{l}\text { Measure } \\
\text { Time (s) }\end{array}$ & Advantages & Disadvantages \\
\hline \multicolumn{6}{|c|}{ STEADY-STATE METHODS } \\
\hline $\begin{array}{l}\text { Guarded hot } \\
\text { plate }^{b}\end{array}$ & $113-973$ & $0.01-6$ & $\begin{array}{l}\text { From hours to } \\
\text { weeks }\end{array}$ & $\begin{array}{c}\text { High } \\
\text { accuracy, } \\
\text { adjustable to the } \\
\text { sample } \\
\text { thickness }\end{array}$ & $\begin{array}{c}\text { Time } \\
\text {-consuming, large } \\
\text { specimen, not suitable } \\
\text { for film-like } \\
\text { samples }\end{array}$ \\
\hline $\begin{array}{l}\text { Heat flow } \\
\text { Meter }^{b}\end{array}$ & $173-473$ & $<0.3$ & $\begin{array}{c}\text { Shorter than } \\
\text { guarded hot plate }\end{array}$ & $\begin{array}{c}\text { Simple } \\
\text { construction and } \\
\text { operation }\end{array}$ & $\begin{array}{c}\text { Measurement } \\
\text { uncertainty, } \\
\text { non-absolute method }\end{array}$ \\
\hline
\end{tabular}

TRANSIENT METHODS

\begin{tabular}{|c|c|c|c|c|c|}
\hline $\begin{array}{c}\text { Transient plane } \\
\text { source }^{c}\end{array}$ & $238-1273$ & $0.001-1800$ & $\begin{array}{c}\text { Few } \\
\text { seconds }\end{array}$ & $\begin{array}{c}\text { Rapid and } \\
\text { precise, wide } \\
\text { temperature and } \\
\text { thermal conductivity } \\
\text { range }\end{array}$ & $\begin{array}{c}\text { Require } \\
\text { entirely planar side of } \\
\text { sample, not } \\
\text { suitable for } \\
\text { powders or } \\
\text { granules }\end{array}$ \\
\hline Laser flash $^{\mathrm{c}}$ & $153-3073$ & $0.1-1000$ & $1-2$ & $\begin{array}{l}\text { Wide } \\
\text { temperature range, } \\
\text { small sample, fast, } \\
\text { accuracy at high } \\
\text { temperature }\end{array}$ & $\begin{array}{c}\text { More expensive, not } \\
\text { suitable for } \\
\text { insulation } \\
\text { materials }\end{array}$ \\
\hline $\begin{array}{l}\text { Modulated } \\
\text { DSC }^{c}\end{array}$ & $190-670$ & $0.1-1$ & $10-100$ & Sensitive and accurate & $\begin{array}{l}\text { Expensive than } \\
\text { conventional DSC }\end{array}$ \\
\hline $3 \omega$ method $^{c}$ & $308-773$ & $0.2-20$ & $\begin{array}{c}\text { Few } \\
\text { seconds }\end{array}$ & $\begin{array}{l}\text { Wide } \\
\text { temperature range, } \\
\text { acceptable } \\
\text { accuracy, } \\
\text { and insensitive to } \\
\text { black-body } \\
\text { radiation }\end{array}$ & $\begin{array}{l}\text { Not suitable for } \\
\text { electrically conductive } \\
\text { samples }\end{array}$ \\
\hline $\begin{array}{l}\text { Transient } \\
\text { hot-wire }^{\text {a }}\end{array}$ & $123-473$ & $0.005-500$ & $\begin{array}{c}10^{-3}-1 \\
\text { (fluid) } \\
10 \\
\text { (solid) }\end{array}$ & $\begin{array}{l}\text { Fast, } \\
\text { accurate }\end{array}$ & $\begin{array}{l}\text { Limited to materials } \\
\text { with low electrical } \\
\text { conductivity (bare } \\
\text { wire), delicate thin wire }\end{array}$ \\
\hline
\end{tabular}

${ }^{a}$ Considered as a primary method. ${ }^{\mathrm{b}}$ Considered as a primary method for low thermal conductivity measurements.

${ }^{\mathrm{c}}$ Considered as a secondary method. 
A non-steady-state or transient technique records a measurement during a heating process and takes advantage of temperature variation over time, leading to a reduction of the heat convection within fluids due to the use of short-time periods on which this effect can be easily identified. Compared to the steady-state techniques, these measurements can be performed relatively quickly [10]. In addition, the amount of sample needed for the measurements is small [4]. Numerous solutions have been derived for the transient heat conduction equation by using one-, two-, or three-dimensional geometries. Generally, transient methods employ probes or wires and work at high temperature and pressure [3,4]. The most extended unsteady methods - transient plane source, laser flash, modulated DSC, $3 w$ method, or transient hot-wire (THW)-are also summed up in Table 1, along with their principal characteristics.

Furthermore, methods can be classified as primary and secondary depending on their metrological quality [1,3]. According to the Comité Consultatif pour la Quantité de Matière, a primary method is a completely described and understood method in which uncertainty and standard results are accepted [1].

\subsection{Transient Hot-Wire}

Transient hot-wire (THW) constitutes an intrusive technique that can be used for measuring the thermal conductivity of non-electrically conductive materials, mostly liquids [4]. In case of measuring electrically conductive samples, the wire must be coated with a protective insulating layer [12]. THW is simple in construction and plays an important role in accurately and quickly measuring thermal conductivity of fluids [13]. As mentioned, it is considered as a primary method and was identified as an appropriate technique for obtaining reference data. THW is an absolute method with a working equation and a complete set of corrections reflecting the departure from the ideal model [3]. Toluene, benzene, and water were proposed by the IUPAC as primary standard liquids for the measurement of thermal conductivity, and they were measured with this method with an accuracy of $1 \%$ [3]. Many researchers have used this technique to estimate the thermal conductivity of a wide variety of materials such as nanofluids [14-16], nanocomposites [17], gases [18], and aqueous solutions [19].

The theory of the THW is well-known and can be found elsewhere [20,21]. The ideal mathematical model is an infinite vertical thin line heat source of zero heat capacity and infinite thermal conductivity immersed in an infinite, stationary, incompressible, and isotropic medium with properties independent of the temperature, and in thermodynamic equilibrium with the wire. When a stepwise constant heat flux per unit length is applied to the wire, it generates pure conductive heat flux that will be transferred from the wire to the immersed material.

To obtain the governing equation of the THW method, Equation (1) must be particularized by applying the following initial and boundary conditions:

$$
\begin{array}{cc}
\Delta T(r, t)=0, & t \leq 0, \forall r ; \\
\lim _{r \rightarrow 0}\left(r \frac{\partial T}{\partial r}\right)=-\frac{\dot{q}}{2 \pi \lambda}, & t \geq 0, r=0 ; \\
\Delta T(r, t)=0, & t \geq 0, r \rightarrow \infty
\end{array}
$$

where $r, t$, and $\dot{q}$ stand for the radial distance from the centre of the wire, the time, and the constant heat flux per unit length, respectively. Equation (1), particularized with the above initial and boundary conditions, constitutes a standard differential equation and was analytically solved by Carslaw and Jaeger [22] as

$$
\Delta T(r, t)=\frac{\dot{q}}{4 \pi \lambda} \int_{\frac{r^{2}}{4 \alpha t}}^{\infty} \frac{e^{-u}}{u} d u
$$


in which $\alpha$ is the thermal diffusivity of the fluid. The last factor of Equation (3) is the so-called exponential integral, which can be expressed as a series expansion [23]:

$$
E_{1}(z)=\int_{z}^{\infty} \frac{e^{-u}}{u} d u=-\gamma-\ln (z)-\sum_{k=1}^{n} \frac{(-1)}{k ! k} z^{k}, \quad z \in \mathbb{C},|\arg (z)|<\pi
$$

where $\gamma$ is the Euler constant. Small values of $r^{2} / 4 \alpha t$ fulfil the requirements of Equation (4). At the wire surface, $r=r_{0}$, the temperature is uniform and equal to the temperature of the conducting medium, and, therefore,

$$
\Delta T\left(r_{0}, t\right)=\frac{\dot{q}}{4 \pi \lambda}\left[\ln \left(\frac{4 \alpha t}{r_{0}^{2} e^{\gamma}}\right)-\sum_{k=1}^{\infty} \frac{1}{k ! k}\left(-\frac{r_{0}^{2}}{4 \alpha t}\right)^{k}\right]
$$

If the radius of the wire is small enough such that $r_{0}^{2}<<4 \alpha t$, the sum can be neglected, obtaining the widely spread THW equation [12]:

$$
\Delta T\left(r_{0}, t\right)=\frac{\dot{q}}{4 \pi \lambda} \ln \left(\frac{4 \alpha t}{r_{0}^{2} e^{\gamma}}\right)
$$

This governing equation constitutes a linear relationship between the temperature rise of the fluid and the natural logarithm of the time. The slope allows one to obtain the thermal conductivity of the immersed medium. In practice, the use of the THW technique introduces a set of departures from the ideal model, presented in equation, and the ideal temperature rise can be written as [20]:

$$
\Delta T_{\mathrm{id}}\left(r_{0}, t\right)=\Delta T_{\exp }(t)+\sum_{i} \delta T_{\mathrm{i}}(t)
$$

where $\Delta T_{\mathrm{id}}\left(r_{0}, t\right), \Delta T_{\exp }(t)$ and $\delta T_{\mathrm{i}}(t)$ stand for the ideal temperature rise obtained from Equation (6), the experimentally measured temperature rise, and the $i$-th temperature correction, respectively. Healy et al. [24] obtained the analytical expressions for all these corrections, which approach the experimental temperature rise. Some recommendations concerning the use of each $\delta T_{\mathrm{i}}$ have been proposed by Nieto de Castro and Lourenço [3]. These effects should be minimized to obtain reliable thermal conductivity data.

Standard instruments based on the THW method have been manufactured over the years. Generally speaking, these instruments consist of a metallic wire, used as line heat source as well as temperature sensor, which is soaked within the testing fluid. Temperatures of the wire as well as the fluid are increased by a constant heat flux supplied by the wire itself. The temperature rise depends on the thermal conductivity of the fluid in which the hot-wire is submerged. The higher the thermal conductivity, the lower the temperature rise, due to increased thermal dissipation from the wire to the surrounding fluid [5,25]. Most of the conventional THW instruments use platinum wires as probes due to the linear relationship between the electrical resistance and the temperature. Shi et al. [26] investigated the effect of fluid radiation on the measurements of the thermal conductivity of propane and designed a transient hot-wire cell for measurements of both thermal conductivity and thermal diffusivity. The cell used two platinum wires of $12.7 \mu \mathrm{m}$ in diameter, each of different length. Vatani et al. [27] presented the design, fabrication, and characterization of a transient hot-wire device for measuring the thermal conductivity of non-conductive fluids. The probe used was a $20 \mu \mathrm{m}$-diameter platinum hot-wire. Mylona et al. [28] used a THW apparatus to carry out thermal conductivity measurements of pure argon, methane, propane, and a methane:propane binary mixture along several isotherms at pressures up to $33 \mathrm{MPa}$. The device presented two wires made of platinum with diameters approximately $10 \mu \mathrm{m}$. Vélez et al. [29] investigated the wire-length dependence of transient hot-wire tests. Thermal conductivities of water Ih-ice, and $n$-eicosane, were measured by an apparatus based on the transient hot-wire method. The core of this device was composed by three platinum wires of different lengths with a diameter of $50 \mu \mathrm{m}$. 
Likewise, wires made of different materials were also studied. Franco [30] developed an apparatus for the measurement of the thermal conductivity of samples of non-metallic materials whose thermal conductivity is quite low, between 0.2 and $4 \mathrm{~W} \mathrm{~m}^{-1} \mathrm{~K}^{-1}$. Thermal conductivity was measured by tracking the thermal pulse propagation induced in the sample by a heating source consisting of a nickel alloy wire. Azarfar et al. [13] constructed and evaluated a low-cost transient hot-wire device for the measurement of thermal conductivity of fluids with the same accuracy of the conventional methods. In this case, a copper microwire of $80 \mu \mathrm{m}$ diameter was chosen in contrast to conventional transient hot-wire devices, which use platinum wire, as mentioned above. Castán-Fernández et al. [31] developed an apparatus for the measurement of the thermal conductivity of geothermal grouting materials. This device was constructed using a wire made of nichrome (nickel and chromium alloy) with a diameter of $0.2 \mathrm{~mm}$. Tian et al. [32,33] developed a thermal conductivity cell for the measurement of electrically conducting fluids, which was employed to determine the thermal conductivity of poly (acrylic acid) in water and poly (acrylic acid)-Na in water. Two tantalum wires of different lengths with diameter of $25.4 \mu \mathrm{m}$ and coated with a layer of tantalum pentoxide were used as heat sources.

\section{Experimental Setup}

\subsection{Materials}

Water (W) with a resistivity of $18.2 \mathrm{M} \Omega \mathrm{cm}$ was obtained through a Milli-Q 185 Plus system from Millipore (Watford, UK). Ethylene glycol (EG) and propylene glycol (PG), both with a 99.5\% mass purity, were purchased from Honeywell (Seelze, Germany) and SigmaAldrich (St. Louis, MO, USA), respectively, and $n$-tetradecane $\left(n-\mathrm{C}_{14}\right)$ and $n$-hexadecane $\left(n-\mathrm{C}_{16}\right)$ were acquired from Alfa Aesar (Haverhill, MA, USA), both $n$-alkanes with mass purities of $99 \%$. MgO nanoparticles were provided by IoLiTec (Heilbronn, Germany), mass purity of $99 \%$, with a pseudo-spherical shape (nominal size diameter by manufacturer of $35 \mathrm{~nm}, 45 \pm 3 \mathrm{~nm}$ by TEM [34], $39.01 \mathrm{~nm}$ by XRD [35]) and a certain level of polydispersity (polidispersity index of 0.32 [34]). Further characterization of these nanoparticles was accomplished in previous studies [34,35].

The ethylene glycol:water 50:50 vol\% mixture (EG:W 50:50 vol\%) was prepared by weighing specific amounts of each component to achieve the required volume fraction. $\mathrm{MgO} / \mathrm{n}-\mathrm{C}_{14}$ nanofluid were prepared at 1,5 , and $10 \mathrm{wt} \%$ by dispersing $\mathrm{MgO}$ nanoparticles within $n-\mathrm{C}_{14}$ in an ultrasonic homogenizer Bandelin Sonopuls HD 2200 (Berlin, Germany) with a sonication time of $30 \mathrm{~min}$. All samples were weighed in a Sartorius analytical balance model CPA225 (Göttingen, Germany) with an uncertainty of $0.01 \mathrm{mg}$.

\subsection{Experimental Procedure}

THW-L2 device (Thermtest Inc., Hanwell, NB, Canada) based on the transient hot-wire method is especially designed to measure thermal conductivity of fluids in agreement with ASTM D7896-14 in the range 0.01 to $2 \mathrm{~W} \mathrm{~m}^{-1} \mathrm{~K}^{-1}$. Figure 1 depicts the layout of the commercial experimental arrangement. An EchoTerm Dry Bath (2) is coupled with the THW-L2 device (1), which allows one to maintain the studied fluid at the test temperature. In this study, tests were performed in the temperature range 283.15 to $333.15 \mathrm{~K}$.

The sensor where the wire is welded (5) is the main element of the above-mentioned device. Its structure is based on an alumel wire of $60 \mathrm{~mm}$ in length and $0.1 \mathrm{~mm}$ diameter connected to the THW-L2 instrument by an isolated cable. This apparatus includes a sample container (3) and a sample cell (4), where the tested fluid is introduced to perform the measurements. The sensor is inserted within the sample cell, and both of them are introduced in the dry bath. 


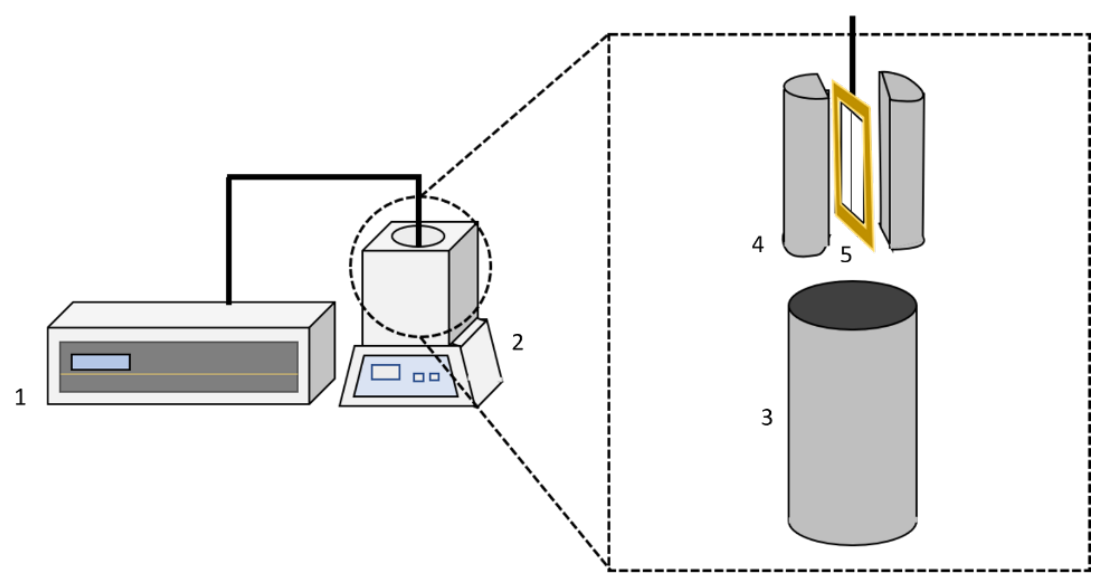

Figure 1. Scheme of the thermal conductivity device: (1) THW-L2 device, (2) EchoTerm Dry Bath, (3) sample container, (4) sample cell, and (5) THW sensor.

The device was operated using the Beta version of the Thermtest THW software. Before starting any measurement, this software allows one to perform a power test in order to adjust the applicable heating power for each fluid in such a way that leads to a certain temperature rise, depending on the viscosity of the fluid. In this work, tests were performed in a temperature rise range of 2.0 to $2.8 \mathrm{~K}$. The software records the temperature history during the transient heating of the sample from the change of the electrical resistivity of the wire. Then, as usual in THW technique, the thermal conductivity is obtained from the slope of the temperature rise over the logarithm of the time in the linear region, as indicated in Equation (6).

Hereunder, three independent experiments comprised of sets of six repetitions at each studied temperature in the range 283.15 to $333.15 \mathrm{~K}$ were carried out to ensure the repeatability of the thermal conductivity values, with the duration of each measurement being $1 \mathrm{~s}$. Temperature stabilization of the sample was allowed between each test.

\section{Results and Discussion}

\subsection{Validation of the Method}

As a first step in the implementation of a new device to obtain experimental values of any thermophysical property, a set of tests to validate the technique should be mandatory, though often omitted [12]. Thereby, we observed the goodness of the application of the THW theoretical model by comparing the measured temperature rise with the one obtained from Equation (6) in the temperature range 283.15 to $333.15 \mathrm{~K}$. As an example of the operation of the conductivity meter, Figure 2 shows raw data of a THW test with Milli-Q water as working fluid. The $\Delta T_{\text {exp }}-\ln (t)$ relationship is displayed following Equation (6) and with a linear tendency over $100 \mathrm{~ms}$, as usual [12,36], highlighting this zone with a shading. Therefore, data below this time should be disregarded (non-shaded zone in Figure 1) to accomplish good metrological quality in the determination of the thermal conductivity, as explained by Antoniadis et al. [12].

The procedure explained above was applied to each fluid considered in this work, and a least squares linear fitting was performed in the time range from 300 to $800 \mathrm{~ms}$ of the measured $\Delta T_{\exp }-\ln (t)$ charts, in which the linear trend can be guaranteed. Figure 3 accounts for the comparison between the experimental temperature rises $\left(\Delta T_{\exp }\right)$ and those obtained from the linear regressions $\left(\Delta T_{\text {reg }}\right.$ ) of the three independent tests for $\mathrm{W}, \mathrm{EG}, \mathrm{PG}, \mathrm{EG}: \mathrm{W}$ $50: 50 \mathrm{vol} \%$ mixture, $n-\mathrm{C}_{14}$, and $n-\mathrm{C}_{16}$, up to $1 \mathrm{~s}$. The agreement is within $\pm 1 \%$ ( $95 \%$ level of confidence), which directly impacts on the repeatability of the device, as discussed below. 


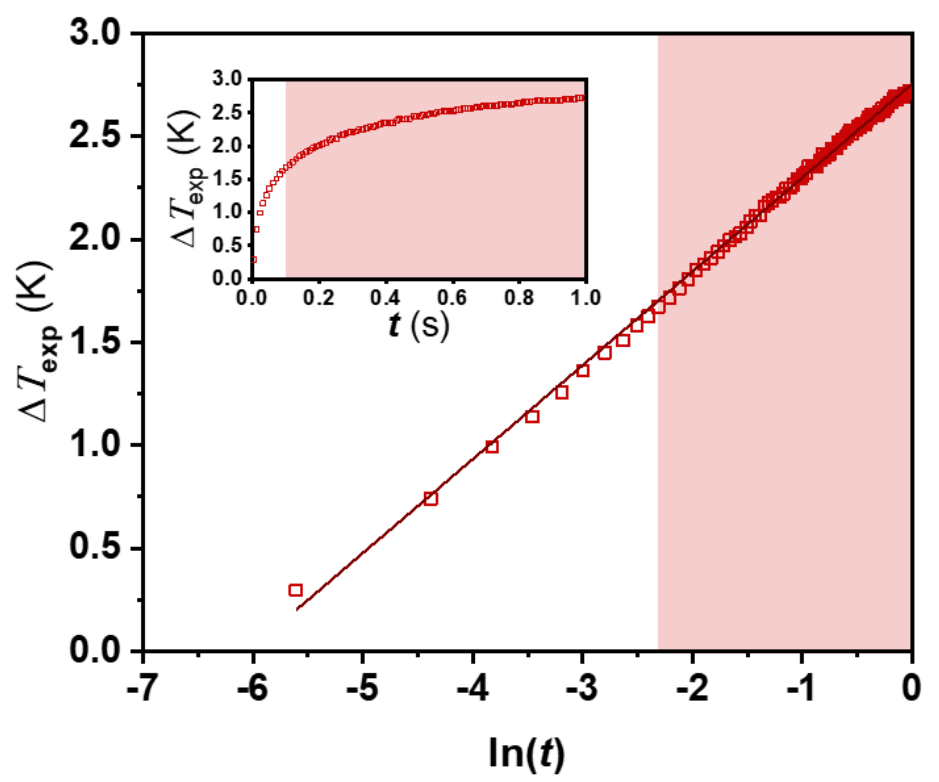

Figure 2. Experimental temperature rise, $\Delta T_{\text {exp }}$, over $\ln (t)(\square)$ for water at $303.25 \mathrm{~K}$ and linear fitting (一) from Equation (6). Inset: raw experimental data.

Tests were performed in such a way that the obtained temperature rise followed the recommendations of the manufacturer (2-3 K for low viscosity samples and 3-4 K for high viscosity ones). To accomplish this fact, the software runs a preliminary test prior to any measurement to determine an appropriate heating power to achieve the required temperature rise, as above-mentioned.

Above results show that there are some systematic and random deviations on these thermal conductivity experiments, which come from departures between the assumed mathematical model and the current measured data. Here, we present a throughout analysis of the source of these uncertainties based on the corrections derived by Healy et al. [24]. Throughout these corrections, the ones applicable to our experimental device are those that come from the thermophysical properties of the wire (non-zero heat capacity and finite thermal conductivity), $\delta T_{1}$; outer boundary conditions, $\delta T_{2}$; radial convection and viscous dissipation, $\delta T_{4}$; radiation heat transfer, $\delta T_{5}$; variable fluid properties, $\delta T_{7}$; and truncation error of the exponential integral, $\delta \mathrm{T}_{9}$, respectively. This selection agrees with the recommendations published by Nieto de Castro and Lourenço [3]. A careful examination of these absolute deviations was performed, and results are summarized in Table 2.

None of the deviations exceeds $0.01 \%$, in line with the level of deviation accepted in the literature $[20,24,36]$. This means that the design of the THW-L2 instrument was carefully performed taking into account these corrections to minimize them. Nevertheless, as previously reported, we found a disagreement of $1 \%$ between the experimental temperature rise and the regressed one; $99 \%$ of this deviation comes from other effects that are not usually considered in the literature, such as from the assumption of constant heating rate. Therefore, it is clear that the mathematical model established by Equation (6) is widely satisfied except for these non-reported effects, which should be caused by the existence of some tiny curvature in the $\Delta T_{\exp }-\ln (t)$ relationship, due to disregarding the needed time to fully develop the free-convection regime [20]. 

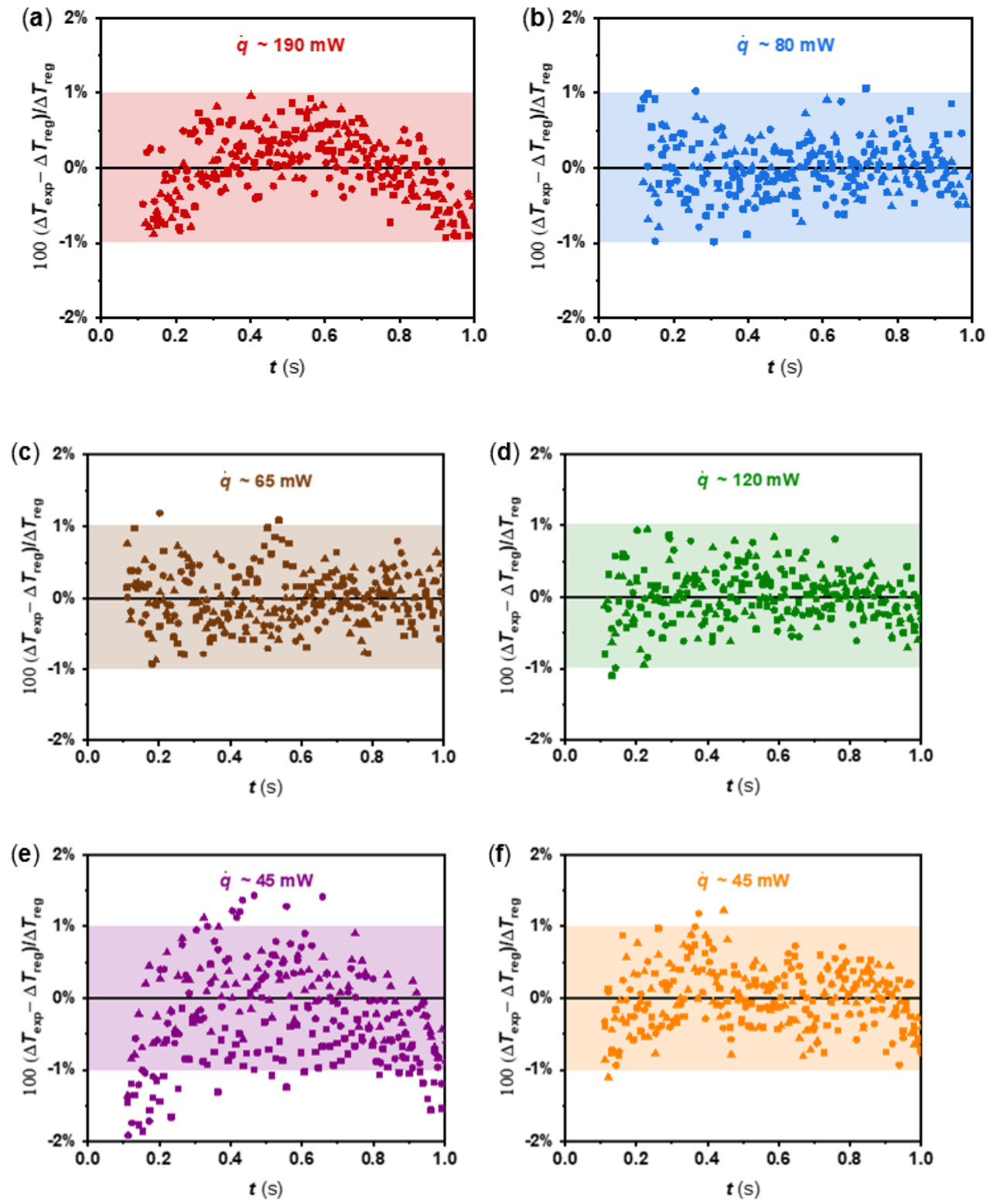

Figure 3. Percentage deviations between $\Delta T_{\text {exp }}$ data and $\Delta T_{\text {reg }}$ determined by Equation (6) from the different tests (• Test 1, $\mathbf{\Delta}$ Test 2, and $\boldsymbol{\square}$ Test 3) as a function of time at different heat flux per unit lengths, $\dot{q}$, for (a) water, (b) ethylene glycol, (c) propylene glycol, (d) ethylene glycol:water 50:50 vol\%, (e) $n$-tetradecane, and (f) $n$-hexadecane.

Table 2. Contribution of each $\left|\delta T_{\mathrm{i}}\right|$ in Equation (7), averaged for the different fluids (W, EG, PG, EG:W 50:50 vol\% mixture, $n-C_{14}$, and $\left.n-C_{16}\right)$ at $303 \mathrm{~K}$.

\begin{tabular}{ccc}
\hline Corrections & $\left|\delta T_{\mathbf{i}}\right| \mathbf{( K )}$ & $\left|\delta T_{\mathbf{i}}\right| / \Delta T_{\text {exp }}(\%)$ \\
\hline$\delta T_{1}$ & $2.5 \times 10^{-4}$ & $1 \times 10^{-2}$ \\
$\delta T_{2}$ & $1.2 \times 10^{-4}$ & $4 \times 10^{-3}$ \\
$\delta T_{4}$ & $2.5 \times 10^{-13}$ & $1 \times 10^{-11}$ \\
$\delta T_{5}$ & $1.7 \times 10^{-9}$ & $7 \times 10^{-8}$ \\
$\delta T_{7}$ & $2.4 \times 10^{-12}$ & $1 \times 10^{-10}$ \\
$\delta T_{9}$ & $2.2 \times 10^{-10}$ & $1 \times 10^{-8}$ \\
\hline
\end{tabular}

\subsection{Repeatability and Comparison with Literature Data}

Thermal conductivity values of W, EG, PG, EG:W 50:50, n- $\mathrm{C}_{14}$, and $n-\mathrm{C}_{16}$ at the temperature range 283.15 to $333.15 \mathrm{~K}$, with a $10 \mathrm{~K}$ temperature step, were determined for 
the three independent tests following Equation (6). The obtained values were compared to each other in Figure 4, obtaining deviations less than 3\% for all the checked fluids over the entire temperature range. An average repeatability level of $0.58 \%$ over the studied temperature range and in the thermal conductivity range 0.130 to $0.700 \mathrm{~W} \mathrm{~m}^{-1} \mathrm{~K}^{-1}$ can be established. This repeatability value is in agreement with the deviations of the experimental temperature rise with respect to the ideal one established in Figure 3 and discussed in the last section. It is noteworthy that the deviations for the different fluids do not show temperature dependence. The scattering of values shown in Figure 4 confirms that the device and the operation mode are reliable from the repeatability point of view.

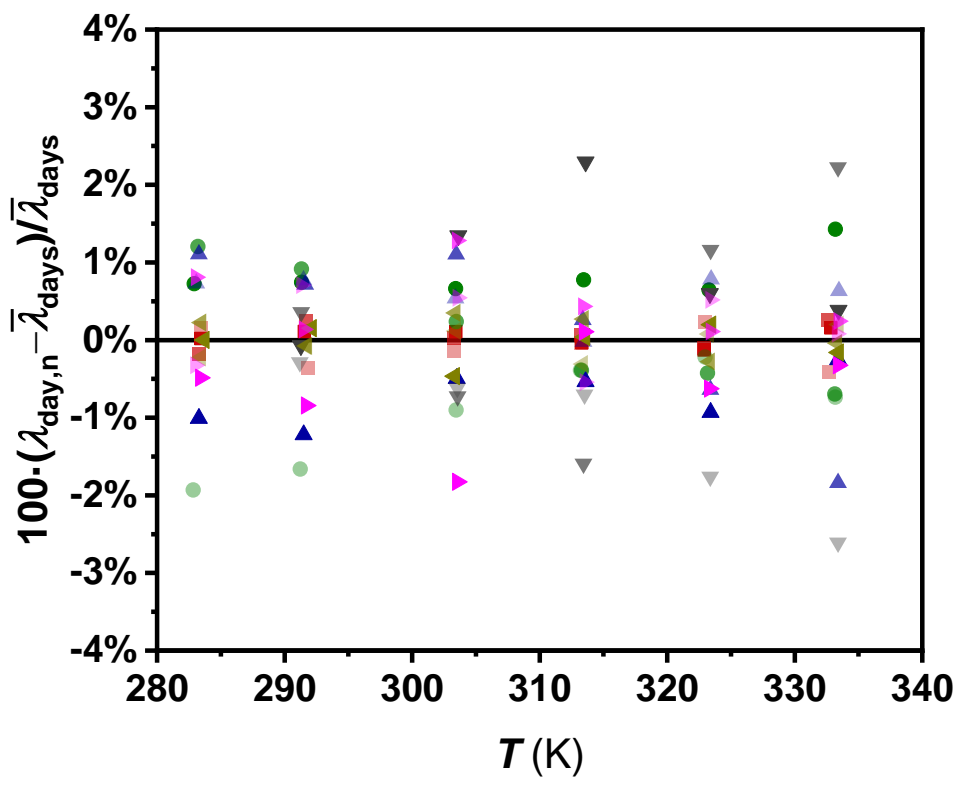

Figure 4. Percentage thermal conductivity deviations between sets of measurements vs. temperature for water ( $\square$ Test 1, $\square$ Test 2, $\square$ Test 3), ethylene glycol ( $\Delta$ Test 1, $\Delta$ Test 2, $\Delta$ Test 3), propylene glycol ( $\triangleright$ Test 1, $\triangleright$ Test 2, $\triangleright$ Test 3), ethylene glycol:water 50:50 vol\% (• Test 1, • Test 2, Test 3), $n$-tetradecane $(\triangleleft$ Test $1, \triangleleft$ Test $2, \triangleleft$ Test 3$)$, and $n$-hexadecane $(\nabla$ Test $1, \nabla$ Test $2, \nabla$ Test 3$)$.

The previous averaged results for $\mathrm{W}, \mathrm{EG}, \mathrm{PG}, \mathrm{EG}: \mathrm{W} 50: 50$, and $n-\mathrm{C}_{14}$ were compared for each temperature and fluid with available literature values [37-49], as shown in Figure 5. The minimum and maximum deviations obtained are, respectively, $0.010 \%$ and $2.6 \%$ for W [37]; $0.70 \%$ and $6.6 \%$ for EG [38-43]; $2.2 \%$ and $5.8 \%$ for PG [43]; $0.20 \%$ and $4.3 \%$ for EG:W $50: 50$ [44-46]; and $2.1 \%$ and $7.4 \%$ for $n-C_{14}$ [47-49]. It must be pointed out that there is not an agreement in literature data of EG:W 50:50 that reaches deviations between the reported references [44-46] up to $3.3 \%$. Consequently, this contributes to the scattering of deviations plotted in Figure 5d. The maximum deviations with respect to the studies by Said et al. [44] and Krishnan and Nagajaran [45] are 2.9\% and 3.6\%, respectively, while the maximum deviation with respect to Melinder [46] is $-4.4 \%$. This last result contradicts the general tendency observed for the rest of the studied fluids $\left(\lambda_{\exp }>\lambda_{\text {lit }}\right)$.

Some systematic discrepancies with no temperature-dependence between our experimental data and literature values can be identified in Figure 5. Thus, an average deviation of $1.1 \%$ is obtained for $\mathrm{W}$, while $4.0 \%$ is reached for EG. Accordingly, with the deviations of the two mentioned fluids, the average deviation for EG:W 50:50 vol\% is 2.1\%. Due to the similar nature of the PG with regard to the EG, the average deviation of this fluid is similar, reaching $4.6 \%$. It must be taken into account that the highest deviation is found for $n-\mathrm{C}_{14}$ alkane, with an average deviation of $4.8 \%$. These results suggest that, the lower the thermal conductivity of the fluid, the higher the deviation regarding the literature data within the entire temperature range. 
(a)

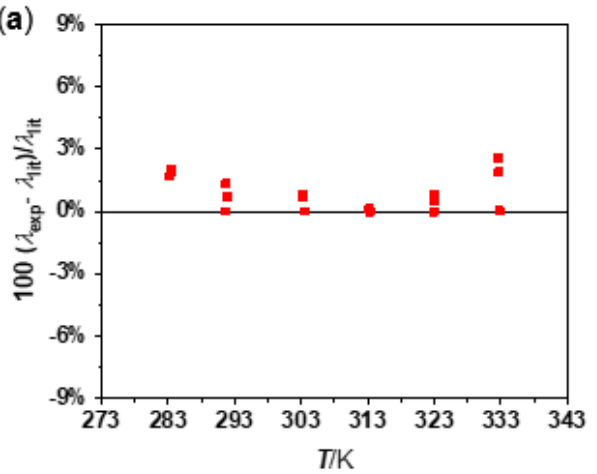

(c)
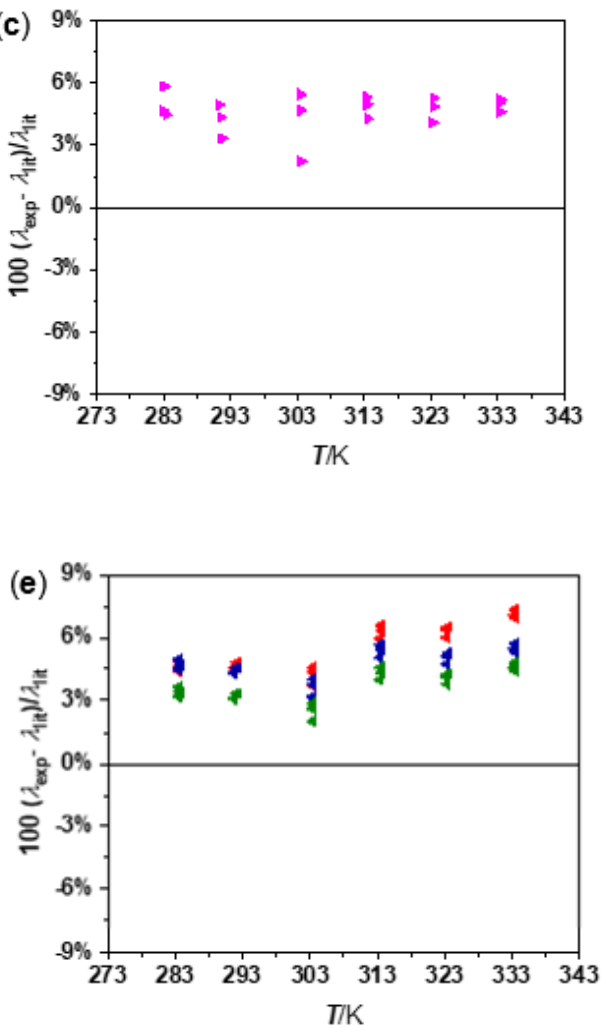

(b) 9

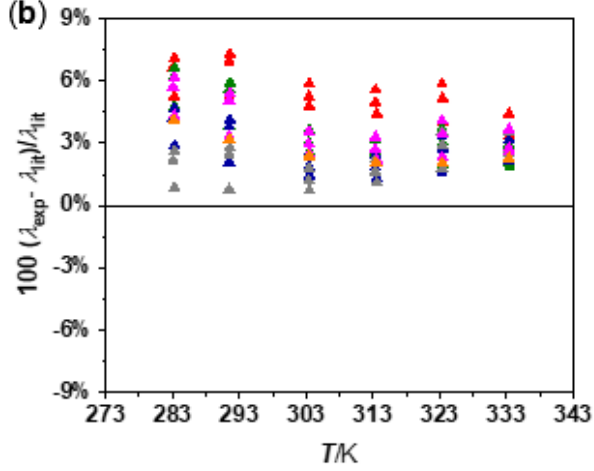

(d)

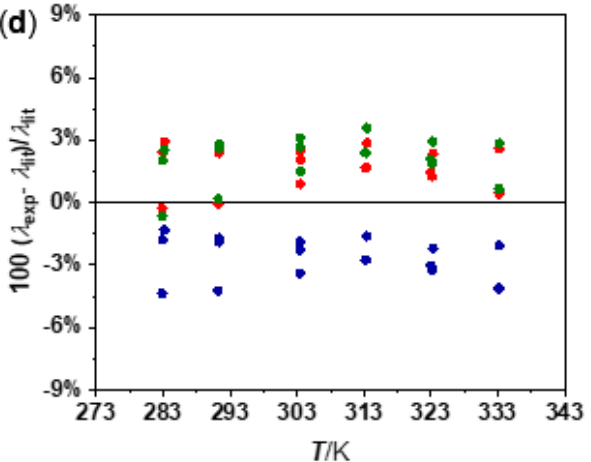

Figure 5. Comparison between experimental and literature thermal conductivity values of (a) water - [37], (b) ethylene glycol $\Delta$ [38] $\Delta$ [39] $\Delta$ [40] $\Delta$ [41] $\Delta$ [42] $\Delta$ [43], (c) propylene glycol $\Delta$ [43], (d) ethylene glycol:water 50:50 vol\% • [44] • [45] • [46], and (e) $n$-tetradecane ४ [47] ४ [48] ४ [49].

\subsection{Proposal of Correction Factor $\Delta \lambda / \lambda$}

Hereafter, we expose a method to correct the systematic deviations found and discussed in the last section. The differentiated deviations of the thermal conductivity depending on the fluid could be explained by an overestimation of the applied heating power, $\dot{q}$, for low thermal conductivity fluids, disallowing the establishment of the stationary regime due to deficient viscous dissipation (high viscosity fluids) or convection effects (low viscosity fluids) [50]. Consequently, a careful analysis of the performance of the equipment with the fluids to be studied should be carried out. This fact entails the use of this device working with common conventional heat transfer fluids or nanofluids (lower than $0.700 \mathrm{~W} \mathrm{~m}^{-1} \mathrm{~K}^{-1}$ ). It should be mentioned that the manufacturer states that its operational thermal conductivity range is 0.01 to $2 \mathrm{~W} \mathrm{~m}^{-1} \mathrm{~K}^{-1}$.

Average deviations between our experimental data and those from the literature are reported in Figure 6 as a function of the mean thermal conductivity, $\bar{\lambda}$, of the fluid in the 
studied temperature range. It must be noted that the variation of the thermal conductivity in this narrow temperature interval is very low, less than $0.079 \mathrm{~W} \mathrm{~m}^{-1} \mathrm{~K}^{-1}$ for all the fluids. Figure 6 evidences that average deviations between experimental and literature thermal conductivity values are lower with increasing thermal conductivity of the fluid. Furthermore, these deviations suggest a linear tendency over the thermal conductivity range. Hence, we propose the following empirical relationship identified as a correction factor, $\Delta \lambda / \lambda$, to correct the above-mentioned systematic deviation effects:

$$
100\left(\frac{\lambda_{\text {exp }}-\lambda_{\text {lit }}}{\lambda_{\text {lit }}}\right)=5.969-8.45 \bar{\lambda}
$$

where $\bar{\lambda}$ (standard deviation of 0.0043 ) is expressed in $\mathrm{W} \mathrm{m}^{-1} \mathrm{~K}^{-1}$. As previously mentioned, this proposed equation is applicable at the temperature range 283.15 to $333.15 \mathrm{~K}$ and the thermal conductivity range 0.100 to $0.700 \mathrm{~W} \mathrm{~m}^{-1} \mathrm{~K}^{-1}$. It should be noted that the actual values of the coefficients of Equation (8) are valid only for this particular instrument, including the software. If researchers use other commercial devices, similar procedure should be accomplished to implement this methodology.

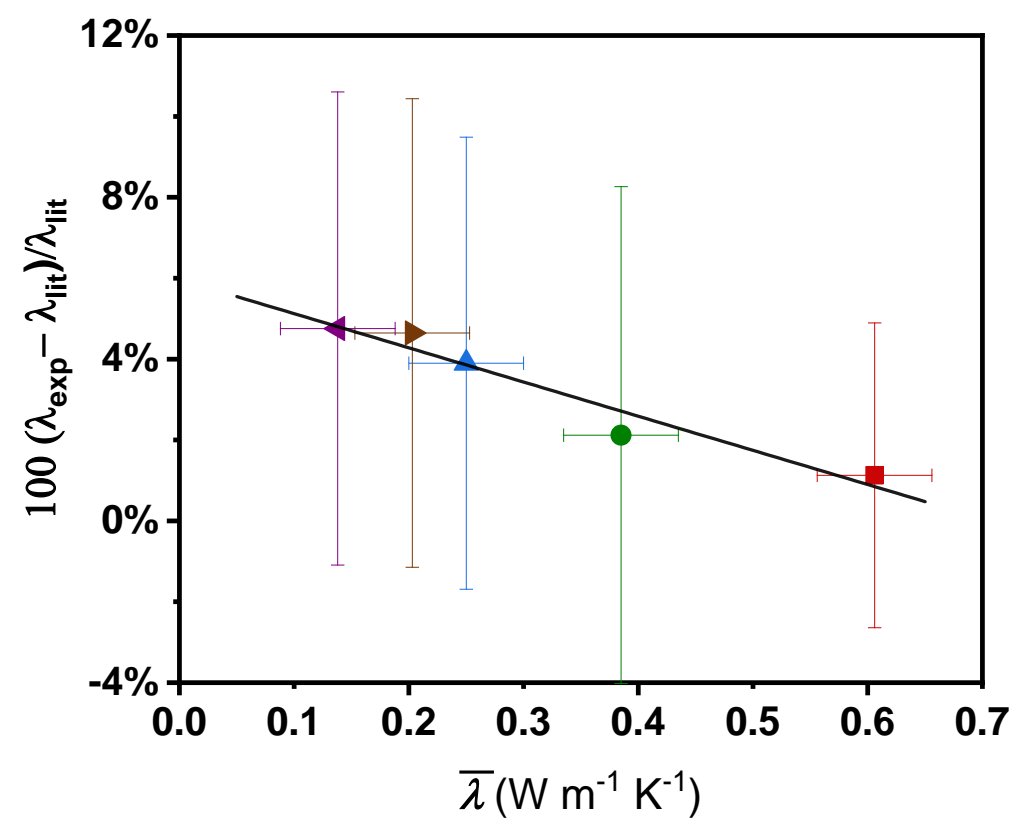

Figure 6. Correction factor, $\Delta \lambda / \lambda$, as a function of the mean thermal conductivity value for water - [37], ethylene glycol $\boldsymbol{\Delta}$ [38-43], propylene glycol $\boldsymbol{\sim}$ [43], ethylene glycol:water 50:50 • [44-46], and $n$-tetradecane 4 [47-49]. (一) Equation (8) Error bars indicate the combined uncertainties for each fluid.

The proposed correction factor was double checked with a pure molecular fluid, $n-C_{16}$, and $\mathrm{MgO} / n-\mathrm{C}_{14}$ nanofluid at mass fractions of 1,5 , and $10 \mathrm{wt} \%$, with both samples being measured at $303 \mathrm{~K}$. Thermal conductivities of the nanofluids were also determined in this work by using a KD2 Pro (Decagon Devices, Pullman, WA, USA) [35]. The employment of Equation (8) provides noteworthy decreases of the discrepancies in THW-L2 values, obtaining reductions in the thermal conductivity deviations from 7.5 to $2.3 \%$ for $n-C_{16}$ [51-54]. In case of $\mathrm{MgO} / \mathrm{n}-\mathrm{C}_{14}$ nanofluids, these reductions were from 9.1 to $4.3 \%$ at $1 \mathrm{wt} \%$, from 8.6 to $3.7 \%$ at $5 \mathrm{wt} \%$, and from 9.3 to $4.4 \%$ at $10 \mathrm{wt} \%$.

Following the methodology and recommendations throughout this paper, it is possible to obtain reliable experimental thermal conductivity data from the THW-L2 device once the correction factor is applied. Taking into account the impacts of the departures of the temperature rise from the ideal model, the repeatability of thermal conductivity values, the 
deviations from literature data, and the proposed correction factor for the raw experimental data, an expanded uncertainty of $5 \%(k=2)$ was estimated.

The proposed methodology can be applied to other commercial instruments following the reported procedure, especially when a proper calibration cannot be afforded. Thus, systematic deviations in thermal conductivity data would be reduced, leading to a standardization of the operation with such devices, in particular for nanofluids research community. However, the suggested correlation cannot be directly employed in other devices and/or fluids, except using the above-reported approach.

\section{Conclusions}

In this work, a commercial instrument based on the transient hot-wire technique, the THW-L2, was implemented and validated to determine the thermal conductivity of fluids. A methodology to correct thermal conductivity values obtained with this commercial device was proposed and carefully analyzed to contribute to improve the reliability of the experimental data that it is usually obtained with such instrumentation.

Nine different fluids were used to test the equipment, namely, water $(W)$, ethylene glycol (EG), propylene glycol (PG), ethylene glycol:water 50:50 vol\% mixture, $n$-tetradecane $\left(n-\mathrm{C}_{14}\right), n$-hexadecane $\left(n-\mathrm{C}_{16}\right)$, and $\mathrm{MgO} / n-\mathrm{C}_{14} 1,5$, and $10 \mathrm{wt} \%$ nanofluids. The selection of the heating power of the wire was performed in such a way that kept the temperature rise between 2 and $3 \mathrm{~K}$. Three independent series of experiments were carried out in the temperature range 283.15 to $333.15 \mathrm{~K}$, recording six measurements per temperature every $10 \mathrm{~K}$. Thermal conductivity was then obtained from the slope of the $\Delta T_{\exp }-\ln (t)$ curve, and these computed data were used to analyze the deviation from the transient hot-wire model and the repeatability of the device. Additionally, a comparison with literature data was performed, with these results allowing one to obtain a relationship to correct the raw experimental data.

The main results achieved in this work are summarized below:

- The behavior of the device was checked by the ability to reproduce the theoretical THW curve and its linearization as $\Delta T_{\exp }-\ln (t)$. Then, the deviation between the experimental data points and their linear fit emerging from the THW theory was found to be $1 \%$. This departure of the experimental behavior from the THW model was discussed and analyzed to figure out which sources have some impact on it.

- Equivalently, from the thermal conductivity data of independent identical tests, the repeatability of the device was found to be $0.58 \%$.

- Moreover, the experimental data here reported were compared to literature values, yielding the following mean deviations: $1.1 \%$ for $\mathrm{W}, 3.9 \%$ for $\mathrm{EG}, 4.6 \%$ for $\mathrm{PG}, 2.1 \%$ for $\mathrm{EG}: \mathrm{W} 50: 50$, and $4.8 \%$ for $n-\mathrm{C}_{14}$.

- The obtained deviations show a systematic dependence on the thermal conductivity range of fluids, and an empirical correction factor has been proposed. This relationship is based on a linear regression of the deviation between experimental values and literature data, as a function of the mean thermal conductivity of the fluid.

- When all these considerations summarized above are taken into account and the recommendations stated in this paper are followed, an expanded $(k=2)$ uncertainty of $5 \%$ is estimated.

- $\quad$ Finally, two different fluids $-n-\mathrm{C}_{16}$ and $\mathrm{MgO} / n-\mathrm{C}_{14}$ nanofluids at 1,5 , and $10 \mathrm{wt} \%$ were also used to check the reliability of this proposal, and reductions in the thermal conductivity deviations from 7.5 to $2.3 \%$ for $n-C_{16}$, and from 9.1 to $4.3 \%$ from 8.6 to $3.7 \%$ and from 9.3 to $4.4 \%$ for $\mathrm{MgO} / n-\mathrm{C}_{14}$ at 1,5 , and $10 \mathrm{wt} \%$, respectively, were obtained. Those new reported values are within the expanded uncertainty gathered in this work.

Following the recommendations of this work, more reliable thermal conductivity values could be obtained when a commercial device is employed, especially in nanofluids research where the use of manufactured devices is quite popular. These proposed critical suggestions may be completed in wider temperature and thermal conductivity ranges 
to cover a broad variety of pure and complex materials besides fluids and nanofluids. Additionally, it would be interesting in future work to check this procedure with fluids other than water (or without water content) with high or moderate thermal conductivity.

Author Contributions: Conceptualization, J.I.P. and L.L.; methodology, J.I.P.; validation, L.L.; formal analysis, J.I.P. and L.L.; investigation, U.C.; resources, L.L.; data curation, J.I.P. and U.C.; writingoriginal draft preparation, U.C.; writing-review and editing, J.I.P. and L.L.; supervision, L.L. All authors have read and agreed to the published version of the manuscript.

Funding: This work was supported by grant PID2020-112846RB-C21 funded by MCIN/AEI/10.13039/ 501100011033, grant PDC2021-121225-C21 funded by MCIN/AEI/10.13039/501100011033 and by "European Union NextGenerationEU/PRTR", project ENE2017-86425-C2-1-R by “Ministerio de Economía y Competitividad" (Spain) and FEDER program. J.I.P. acknowledges the financial support from the Xunta de Galicia (Spain) and FSE Galicia 2014-2020 Program (EU-ESF) under predoctoral grant ED481A-2018/287.

Conflicts of Interest: The authors declare no conflict of interest.

\section{References}

1. Nunes, V.M.B.; Lourenço, M.J.V.; Santos, F.J.V.; Lopes, M.L.S.M.; de Castro, C.A.N. Accurate Measurement of Physicochemical Properties on Ionic Liquids and Molten Salts. In Molten Salts and Ionic Liquids; Wiley: Hoboken, NJ, USA, $2010 ;$ pp. $229-263$.

2. Assael, M.J.; Antoniadis, K.D.; Wakeham, W.A. Historical Evolution of the Transient Hot-Wire Technique. Int. J. Thermophys. 2010, 31, 1051-1072. [CrossRef]

3. Nieto de Castro, C.A.; Lourenço, M.J.V. Towards the Correct Measurement of Thermal Conductivity of Ionic Melts and Nanofluids. Energies 2020, 13, 99. [CrossRef]

4. Palacios, A.; Cong, L.; Navarro, M.E.; Ding, Y.; Barreneche, C. Thermal conductivity measurement techniques for characterizing thermal energy storage materials-A review. Renew. Sustain. Energy Rev. 2019, 108, 32-52. [CrossRef]

5. Paul, G.; Chopkar, M.; Manna, I.; Das, P.K. Techniques for measuring the thermal conductivity of nanofluids: A review. Renew. Sustain. Energy Rev. 2010, 14, 1913-1924. [CrossRef]

6. $\quad$ Buongiorno, J.; Venerus, D.C.; Prabhat, N.; McKrell, T.; Townsend, J.; Christianson, R.; Tolmachev, Y.V.; Keblinski, P.; Hu, L.W.; Alvarado, J.L.; et al. A benchmark study on the thermal conductivity of nanofluids. J. Appl. Phys. 2009, 106, 094312. [CrossRef]

7. Tertsinidou, G.; Assael, M.J.; Wakeham, W.A. The Apparent Thermal Conductivity of Liquids Containing Solid Particles of Nanometer Dimensions: A Critique. Int. J. Thermophys. 2015, 36, 2. [CrossRef]

8. Berger Bioucas, F.E.; Rausch, M.H.; Schmidt, J.; Bück, A.; Koller, T.M.; Fröba, A.P. Effective Thermal Conductivity of Nanofluids: Measurement and Prediction. Int. J. Thermophys. 2020, 41, 55. [CrossRef]

9. Murshed, S.M.S.; Nieto de Castro, C.A. Conduction and convection heat transfer characteristics of ethylene glycol based nanofluids-A review. Appl. Energy 2016, 184, 681-695. [CrossRef]

10. Yüksel, N. The Review of Some Commonly Used Methods and Techniques to Measure the Thermal Conductivity of Insulation Materials. In Insulation Materials in Context of Sustainability; Almusaed, A., Almssad, A., Eds.; InTech: Rijeka, Croatia, 2016.

11. Dubois, S.; Lebeau, F. Design, construction and validation of a guarded hot plate apparatus for thermal conductivity measurement of high thickness crop-based specimens. Mater. Struct. 2015, 48, 407-421. [CrossRef]

12. Antoniadis, K.D.; Tertsinidou, G.J.; Assael, M.J.; Wakeham, W.A. Necessary Conditions for Accurate, Transient Hot-Wire Measurements of the Apparent Thermal Conductivity of Nanofluids are Seldom Satisfied. Int. J. Thermophys 2016, 37, 78. [CrossRef]

13. Azarfar, S.; Movahedirad, S.; Sarbanha, A.A.; Norouzbeigi, R.; Beigzadeh, B. Low cost and new design of transient hot-wire technique for the thermal conductivity measurement of fluids. Appl. Therm. Eng. 2016, 105, 142-150. [CrossRef]

14. Cabaleiro, D.; Nimo, J.; Pastoriza-Gallego, M.J.; Piñeiro, M.M.; Legido, J.L.; Lugo, L. Thermal conductivity of dry anatase and rutile nano-powders and ethylene and propylene glycol-based $\mathrm{TiO}_{2}$ nanofluids. J. Chem. Thermodyn. 2015, 83, 67-76. [CrossRef]

15. Mirbagheri, M.H.; Akbari, M.; Mehmandoust, B. Proposing a new experimental correlation for thermal conductivity of nanofluids containing of functionalized multiwalled carbon nanotubes suspended in a binary base fluid. Int. Commun. Heat Mass Transf. 2018, 98, 216-222. [CrossRef]

16. Liu, W.I.; Malekahmadi, O.; Bagherzadeh, S.A.; Ghashang, M.; Karimipour, A.; Hasani, S.; Tlili, I.; Goodarzi, M. A novel comprehensive experimental study concerned graphene oxide nanoparticles dispersed in water: Synthesise, characterisation, thermal conductivity measurement and present a new approach of RLSF neural network. Int. Commun. Heat Mass Transf. 2019, 109, 104333. [CrossRef]

17. Bouchard, J.; Cayla, A.; Devaux, E.; Campagne, C. Electrical and thermal conductivities of multiwalled carbon nanotubesreinforced high performance polymer nanocomposites. Compost. Sci. Technol. 2013, 86, 177-184. [CrossRef]

18. Pátek, J.; Klomfar, J. Measurement of the thermal conductivity of argon and methane: A test of a transient hot-wire apparatus. Fluid Ph. Equilib. 2002, 198, 147-163. [CrossRef] 
19. Fujiura, K.; Nakamoto, Y.; Taguchi, Y.; Ohmura, R.; Nagasaka, Y. Thermal conductivity measurements of semiclathrate hydrates and aqueous solutions of tetrabutylammonium bromide (TBAB) and tetrabutylammonium chloride (TBAC) by the transient hot-wire using parylene-coated probe. Fluid Ph. Equilib. 2016, 413, 129-136. [CrossRef]

20. De Groot, J.J.; Kestin, J.; Sookiazian, H. Instrument to measure the thermal conductivity of gases. Physica 1974, 75, 454-482. [CrossRef]

21. Hammerschmidt, U.; Sabuga, W. Transient Hot Wire (THW) Method: Uncertainty Assessment. Int. J. Thermophys. 2000, 21, 1255-1278. [CrossRef]

22. Carslaw, H.S.; Jaeger, J.C. Conduction of Heat in Solids, 2nd ed.; Oxford University Press: Oxford, UK, 1959.

23. Abramowitz, H.; Stegun, I.A. Handbook of Mathematical Functions, 9th ed.; Dover Publications: New York, NY, USA, 1972.

24. Healy, J.J.; de Groot, J.J.; Kestin, J. The theory of the transient hot-wire method for measuring thermal conductivity. Phys. B+C 1976, 82, 392-408. [CrossRef]

25. Hong, S.W.; Kang, Y.-T.; Kleinstreuer, C.; Koo, J. Impact analysis of natural convection on thermal conductivity measurements of nanofluids using the transient hot-wire method. Int. J. Heat Mass Transf. 2011, 54, 3448-3456. [CrossRef]

26. Shi, Y.; Sun, L.; Tian, F.; Venart, J.E.S.; Prasad, R.C. Fluid radiation effects in the transient hot-wire technique. J. Therm. Anal. Calorim. 2007, 90, 693-698. [CrossRef]

27. Vatani, A.; Woodfield, P.L.; Dao, D.V. A miniaturized transient hot-wire device for measuring thermal conductivity of nonconductive fluids. Microsyst. Technol. 2016, 22, 2463-2466. [CrossRef]

28. Mylona, S.K.; Yang, X.; Hughes, T.J.; White, A.C.; McElroy, L.; Kim, D.; Al Ghafri, S.; Stanwix, P.L.; Sohn, Y.H.; Seo, Y.; et al. High-Pressure Thermal Conductivity Measurements of a (Methane + Propane) Mixture with a Transient Hot-Wire Apparatus. J. Chem. Eng. Data 2020, 65, 906-915. [CrossRef]

29. Vélez, C.; Reding, B.; Ortiz de Zárate, J.M.; Khayet, M. Thermal conductivity of water Ih-ice measured with transient hot-wires of different lengths. Appl. Therm. Eng. 2019, 149, 788-797. [CrossRef]

30. Franco, A. An apparatus for the routine measurement of thermal conductivity of materials for building application based on a transient hot-wire method. Appl. Therm. Eng. 2007, 27, 2495-2504. [CrossRef]

31. Castán-Fernández, C.; Marcos-Robredo, G.; Rey-Ronco, M.Á.; Alonso-Sánchez, T. Design, Construction and Commissioning of an Apparatus for Measuring the Thermal Conductivity of Geothermal Grouting Materials Based on the Transient Hot Wire Method Proceedings 2018, 2, 1496. [CrossRef]

32. Tian, F.; Sun, L.; Venart, J.E.S.; Prasad, R.C.; Mojumdar, S.C. Development of a thermal conductivity cell with nanolayer coating for thermal conductivity measurement of fluids. J. Therm. Anal. Calorim. 2008, 94, 37-43. [CrossRef]

33. Tian, F.; Sun, L.; Mojumdar, S.C.; Venart, J.E.S.; Prasad, R.C. Absolute measurement of thermal conductivity of poly (acrylic acid) by transient hot wire technique. J. Therm. Anal. Calorim. 2011, 104, 823-829. [CrossRef]

34. Prado, J.I.; Vallejo, J.P.; Lugo, L. A new relationship on transport properties of nanofluids. Evidence with novel magnesium oxide based $n$-tetradecane nanodispersions. Powder Technol. 2022, in press. [CrossRef]

35. Prado, J.I.; Lugo, L. Enhancing the Thermal Performance of a Stearate Phase Change Material with Graphene Nanoplatelets and MgO Nanoparticles. ACS Appl. Mater. Interfaces 2020, 12, 39108-39117. [CrossRef] [PubMed]

36. Beirão, S.G.S.; Ramires, M.L.V.; Dix, M.; de Castro, C.A.N. A New Instrument for the Measurement of the Thermal Conductivity of Fluids. Int. J. Thermophys. 2006, 27, 1018-1041. [CrossRef]

37. Wagner, W.; Pruß, A. The IAPWS Formulation 1995 for the Thermodynamic Properties of Ordinary Water Substance for General and Scientific Use. J. Phys. Chem Ref. Data 2002, 31, 387-535. [CrossRef]

38. Mariano, A.; Pastoriza-Gallego, M.J.; Lugo, L.; Mussari, L.; Piñeiro, M.M. $\mathrm{Co}_{3} \mathrm{O}_{4}$ ethylene glycol-based nanofluids: Thermal conductivity, viscosity and high pressure density. Int. J. Heat Mass Transf. 2015, 85, 54-60. [CrossRef]

39. Peñas, J.R.V.; Ortiz de Zárate, J.M.; Khayet, M. Measurement of the thermal conductivity of nanofluids by the multicurrent hot-wire method. J. Appl. Phys. 2008, 104, 044314. [CrossRef]

40. DiGuilio, R.; Teja, A. Thermal conductivity of poly (ethylene glycols) and their binary mixtures. J. Chem. Eng. Data 1990, 35, 117-121. [CrossRef]

41. Assael, M.J.; Charitidou, E.; Avgoustiniatos, S.; Wakeham, W.A. Absolute measurements of the thermal conductivity of mixtures of alkene-glycols with water. Int. J. Thermophys. 1989, 10, 1127-1140. [CrossRef]

42. Khayet, M.; Zárate, J.M.O.D. Application of the Multi-Current Transient Hot-Wire Technique for Absolute Measurements of the Thermal Conductivity of Glycols. Int. J. Thermophys. 2005, 26, 637-646. [CrossRef]

43. Sun, T.; Teja, A.S. Density, Viscosity, and Thermal Conductivity of Aqueous Ethylene, Diethylene, and Triethylene Glycol Mixtures between $290 \mathrm{~K}$ and 450 K. J. Chem. Eng. Data 2003, 48, 198-202. [CrossRef]

44. Said, Z.; Abdelkareem, M.A.; Rezk, H.; Nassef, A.M. Fuzzy modeling and optimization for experimental thermophysical properties of water and ethylene glycol mixture for $\mathrm{Al}_{2} \mathrm{O}_{3}$ and $\mathrm{TiO}_{2}$ based nanofluids. Powder Technol. 2019, 353, 345-358 [CrossRef]

45. Suseel Jai Krishnan, S.; Nagarajan, P.K. Experimental study on thermal conductivity of solution combustion synthesized MgO nanoparticles dispersed in water and ethylene glycol (50:50) binary mixture. AIP Conf. Proc. 2017, 1832, 050074.

46. Melinder, A. Thermophysical Properties of Aqueous Solutions Used as Secondary Working Fluids. Ph.D. Thesis, KTH Royal Institute of Technology, Stockholm, Sweden, 2007. 
47. Jiang, H.; Xu, Q.; Huang, C.; Shi, L. Effect of temperature on the effective thermal conductivity of n-tetradecane-based nanofluids containing copper nanoparticles. Particuology 2015, 22, 95-99. [CrossRef]

48. Kenisarin, M.M. Thermophysical properties of some organic phase change materials for latent heat storage. A review. Sol. Energy 2014, 107, 553-575. [CrossRef]

49. Kian, K.; Scurto, A.M. Heat Transport Properties of $\mathrm{CO}_{2}$-Expanded Liquids: N-Hexane, n-Decane, and n-Tetradecane. Ind. Eng. Chem. Res. 2017, 56, 12822-12832. [CrossRef]

50. McLaughlin, E.; Pittman, J.F.T. Determination of the Thermal Conductivity of Toluene-A Proposed Data Standard-from 180 to 400k under Saturation Pressure by the Transient Hot-Wire Method I. The Theory of the Technique. Philos. Trans. Royal Soc. A 1971, 270, 557-578.

51. Vélez, C.; Khayet, M.; Ortiz de Zárate, J.M. Temperature-dependent thermal properties of solid/liquid phase change evennumbered n-alkanes: N-Hexadecane, n-octadecane and n-eicosane. Appl. Energy 2015, 143, 383-394. [CrossRef]

52. Mustafaev, R.A. Thermal conductivity of higher saturated n-hydrocarbons over wide ranges of temperature and pressure. J. Eng. Phys. 1973, 24, 465-469. [CrossRef]

53. Monogenidou, S.A.; Assael, M.J.; Huber, M.L. Reference Correlation for the Thermal Conductivity of n-Hexadecane from the Triple Point to $700 \mathrm{~K}$ and up to $50 \mathrm{MPa}$. J. Phys. Chem. Ref. Data 2018, 47, 013103. [CrossRef] [PubMed]

54. Wada, Y.; Nagasaka, Y.; Nagashima, A. Measurements and correlation of the thermal conductivity of liquid n-paraffin hydrocarbons and their binary and ternary mixtures. Int. J. Thermophys. 1985, 6, 251-265. [CrossRef] 